\title{
Autosomal Dominant Polycystic Kidney Disease: New Treatment Options and How to Test Their Efficacy
}

\author{
Rudolf P. Wüthrich Andreas L. Serra Andreas D. Kistler \\ Division of Nephrology, University Hospital, Zürich, Switzerland
}

\section{Key Words}

Autosomal dominant polycystic kidney disease •

End-stage kidney disease $\cdot$ Cyst growth

\begin{abstract}
Autosomal dominant polycystic kidney disease (ADPKD) represents a slowly progressing cystic kidney disorder which evolves into end-stage renal disease in the majority of patients. Currently, there are no established treatments to retard the progression of the disease, but several promising therapeutic options are being tested in ongoing clinical trials. An inherent dilemma for the investigation of therapies in ADPKD is the dissociation of the early onset and constant rate of cyst growth from the delayed but accelerated loss of renal function. In order to prevent the latter, one needs to act on the former, i.e. current belief by experts in the field is that (1) retardation of cyst growth will ultimately improve the loss of glomerular filtration rate, and (2) cyst volume is an ideal surrogate parameter for outcome in early ADPKD. The present review will discuss the utility and the techniques for kidney and cyst volume measurements to assess disease progression in ADPKD, and summarizes ongoing clinical trials testing novel therapeutic options.
\end{abstract}

Copyright $\odot 2009$ S. Karger AG, Basel (c) 2009 S. Karger AG, Basel

$1420-4096 / 09 / 0325-0380 \$ 26.00 / 0$

Fax +41613061234 E-Mail karger@karger.ch www.karger.com

\section{Autosomal Dominant Polycystic Kidney Disease - The Most Frequent Hereditary Renal Disease}

Autosomal dominant polycystic kidney disease (ADPKD) is a well-known chronically progressing cystic renal disease. Approximately 1:800 to 1:1,000 people are affected by the disease, although there are areas where the incidence of this condition is more or less frequent. The disease is inherited in an autosomal dominant fashion, progresses slowly over decades, and manifests clinically with hypertension, flank pain, hematuria and renal cyst infections in adults. Extrarenal manifestations are common but rarely prominent in early disease. The pathogenesis of ADPKD is characterized by cyst development and growth in both kidneys [1,2]. Typically, the size of the kidneys increases from a normal size (150-200 $\mathrm{cm}^{3}$ ) [3] in adolescence to $>1,500 \mathrm{~cm}^{3} /$ kidney. The growing cysts gradually replace the functional renal parenchyma and distort the normal architecture of the kidney. Despite the presence of innumerable cysts in both kidneys, glomerular filtration rate (GFR) is well preserved in most patients up to the age of 30-40 years. Between the ages of 40 and 70 years, however, renal function usually declines in an accelerated fashion. End-stage renal disease (ESRD) with the need for dialysis or transplantation affects approximately $50 \%$ of the patients with ADPKD by the age of 70 years [4].

Prof. Rudolf P. Wüthrich

Division of Nephrology, University Hospital

Rämistrasse 100

CH-8091 Zürich (Switzerland)

Tel. +41 4425533 84, Fax +41 4425545 93, E-Mail rudolf.wuethrich@usz.ch 
In $85 \%$ of the cases, ADPKD is caused by mutations in the PKD1 gene which encodes the ciliary protein polycystin-1. In 15\%, the PKD2 gene which encodes polycystin-2 is mutated. Mutations in other genes may account for some cases but have not yet been characterized. Cases with PKD1 gene mutations have a more severe course, with ESRD occurring at an average age of 54 years which is roughly 10 years earlier than in patients with mutations in the PKD2 gene. Thus, fewer patients with PKD2 mutations reach ESRD during their lifetime [5].

\section{How to Follow Disease Progression: GFR versus Cyst or Kidney Volume}

Currently, changes in GFR are considered the gold standard for quantifying the progression rate in most chronic renal diseases. However, owing to the remarkable capability of intact nephrons to compensate for the loss of functional parenchyma, GFR measurement may fail to disclose ominous changes at early stages of kidney diseases. In his classical paper, Dalgaard [6] reported on 346 individuals from Denmark with polycystic kidneys and found that palpable kidneys appeared in relatively young patients long before the onset of uremia. He concluded that cyst growth preceded and ultimately caused the onset of uremia. Indeed, data from several longitudinal ADPKD cohort studies have now demonstrated that cyst volume growth represents a continuous process which begins in childhood or adolescence [7-10] and precedes GFR decline by years [11], as shown in figure 1 .

Considering the grossly distorted kidney architecture at the time when GFR starts to decline, early intervention before cysts have replaced the bulk of intact renal parenchyma is probably warranted but a treatment effect on GFR would be evident only after several years. GFR is therefore not suitable as a primary end point for clinical studies testing early intervention. There is not much doubt that cyst growth is ultimately responsible for subsequent loss of glomerular filtration through direct (compression) and indirect (e.g. fibrosis) effects. Given the continuous rate of cyst growth during early ADPKD, kidney or cyst volume enlargement is an obvious surrogate endpoint for clinical trials at that stage, and attempts have been made to correlate kidney volume progression with GFR decline in several longitudinal studies by serial imaging.

Ultrasound is inaccurate for determining small changes in renal volume and is not suitable for very large kidneys. Using a long observation period with an average of
7.8 years of follow-up, however, Fick-Brosnahan et al. [7] were able to demonstrate a significant inverse relationship between the rate of kidney volume growth and the rate of GFR decline. Computed tomography (CT) has been used to monitor polycystic kidney volumes in several studies [12-14]. By combining data from a prospective and a retrospective study it could be shown that patients who develop renal insufficiency by the end of follow-up exhibit a markedly higher volume growth [11]. A concern related to the use of serial CT for disease monitoring in ADPKD is the repeated exposure of young patients to ionizing radiation. Therefore, magnetic resonance imaging (MRI) based volumetry is emerging as the method of choice to follow kidney volumes.

The Consortium for Radiologic Imaging Studies of Polycystic Kidney Disease (CRISP) has recently published the results of yearly assessments of kidney and cyst volume measurements by MRI, and GFR by iothalamate clearance in $232 \mathrm{ADPKD}$ patients who were followed over 3 years [9]. In that study, gadolinium-enhanced coronal T1-weighted images were obtained and the volumes of individual kidneys were measured using a stereologic method counting the intersections of the kidney outlines on a superimposed grid and summing the products of the area measurements and slice thickness from the set of contiguous images. A region-based threshold method was used to calculate cyst volumes from T2-weighted coronal images. Although these patients had preserved renal function and no case of nephrogenic systemic fibrosis was reported in any of these patients, the CRISP investigators moved to the use of image sequences obtained without gadolinium enhancement for further follow-up (CRISP II), and did not notice a change in accuracy of the volume measurements [15].

In the CRISP study it was found that total kidney volume and total cyst volume increased exponentially with a mean $( \pm S D)$ annual growth rate of $5.3 \pm 3.9 \%$. The baseline total kidney volume predicted the subsequent rate of increase in volume, independent of age. Furthermore, higher rates of kidney enlargement were found to be associated with a more rapid decrease in renal function. A baseline total kidney volume of $>1,500 \mathrm{~cm}^{3}$ in 51 patients was associated with a decline in GFR by $4.3 \pm$ $8.1 \mathrm{ml} / \mathrm{min} /$ year $(\mathrm{p}<0.001)[9]$.

We have recently validated and extended some of the results of the CRISP study in a Swiss cohort of young ADPKD patients (age 18-42 years) with preserved GFR [10]. Thus we were able to show that kidney volume changes could be reliably assessed with MRI within a time period as short as 6 months. Using a T1-weighted 
Fig. 1. a In patients with ADPKD the GFR remains preserved for decades, but declines in an accelerated mode after the age of 40-50 years. b The total kidney volume increases steadily throughout life in patients with ADPKD. Some patients show only slow progression (mostly PKD2 genotype), whereas others progress more rapidly. Copyright (C) 2008 Massachusetts Medical Society. All rights reserved.
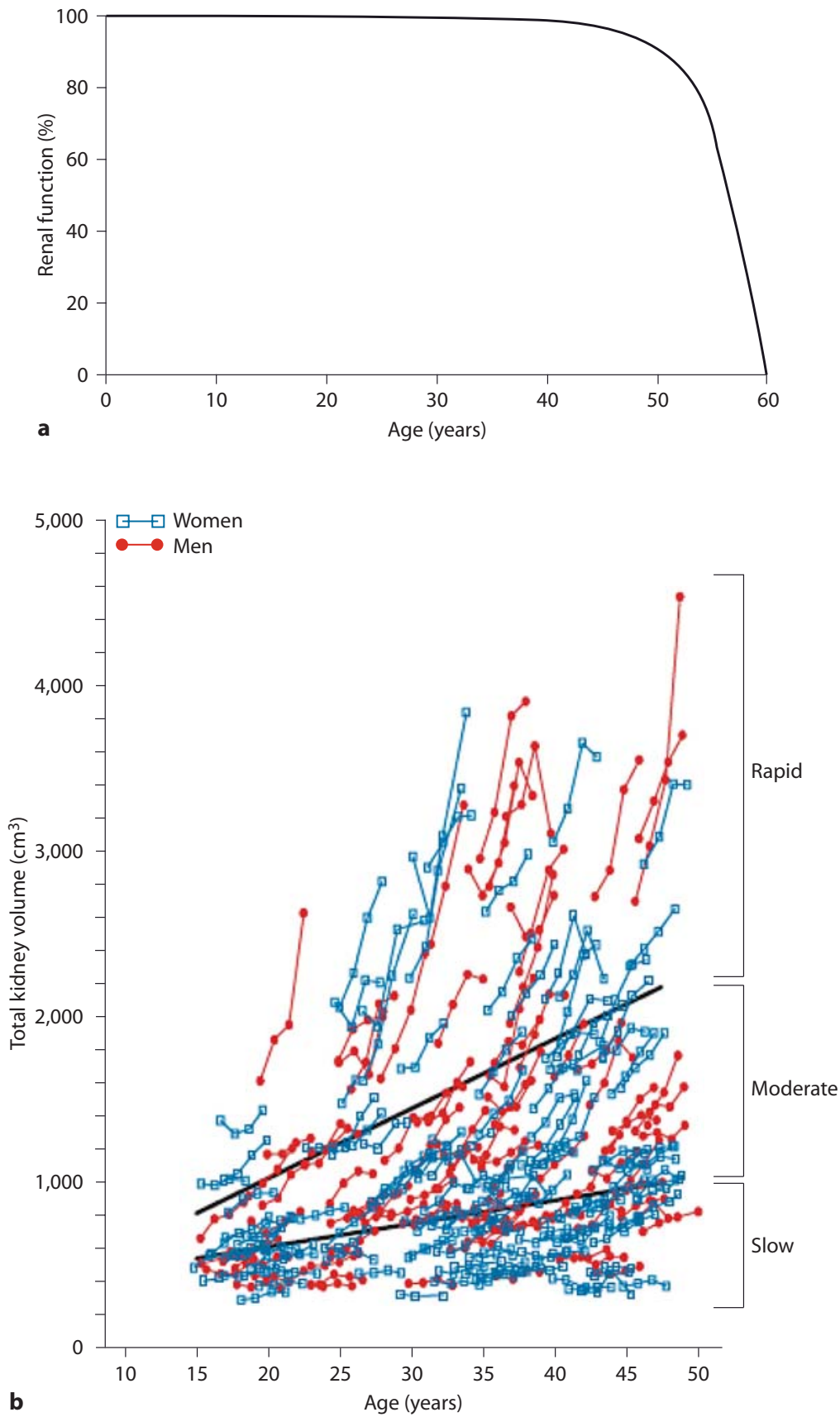

acquisition protocol without gadolinium-based contrast agents we have examined 100 ADPKD patients at months 0 and 6 . The volumes of both kidneys were determined in each patient using a manual segmentation protocol. On each MRI section, the outlines of the kidneys were manually drawn and the renal volumes were calculated by multiplying all outline areas by the section thickness and summing the volume of each section.

Using this approach we could detect a significant increase in total kidney volume of $2.7 \pm 4.8 \%$ within 6 months [10], corresponding to $5.4 \pm 9.5 \%$ /year, which is in very good agreement with the CRISP data. An interest- 
Table 1. Characteristics and cyst growth rates in the Swiss [10] and American [9] ADPKD studies

\begin{tabular}{lcc}
\hline & $\begin{array}{l}\text { Swiss ADPKD } \\
\text { cohort }\end{array}$ & CRISP cohort \\
\hline $\begin{array}{l}\text { Number of patients } \\
\text { Age, years (range) }\end{array}$ & 100 & 232 \\
$\begin{array}{l}\text { Female, \% } \\
\text { GFR or creatinine }\end{array}$ & $31.2 \pm 6.4(18-42)$ & $32.4 \pm 8.9(15-46)$ \\
$\quad$ clearance, $\mathrm{ml} / \mathrm{min}$ & $110 \pm 26$ & 60 \\
$\begin{array}{l}\text { Baseline TKV, } \mathrm{cm}^{3} \\
\text { Annual TKV increase }\end{array}$ & $1,003 \pm 568$ & $107 \pm 28$ \\
$\quad$ In $\mathrm{cm}^{3}$ & $62.2 \pm 136.5$ & $63.4 \pm 69.8$ \\
$\quad$ In \% & $5.36 \pm 9.47$ & $5.27 \pm 3.92$ \\
\hline
\end{tabular}

The characteristics of the Swiss and American ADPKD cohorts were similar. Kidney volume growth and growth rates were also alike. TKV = Total kidney volume.

ing observation was that some patients displayed a significant volume regression which could be attributed to spontaneous rupture of large cysts. Like the CRISP study, we found a high degree of correlation between total kidney volume change and cyst volume change, demonstrating that the total kidney volume growth can be entirely attributed to the growth of the cysts. Because the measurement of total kidney volume is much easier and more reliable than that of cyst volume, the former might be a more precise marker of disease progression. Table 1 summarizes the characteristics and the kidney volume growth rates of the Swiss and the American ADPKD cohorts. A high degree of similarity in terms of baseline characteristics, total kidney volume, and volume growth rates can be noted.

Taken together, there is a growing body of evidence that kidney volume changes can reliably be measured in early ADPKD and that cyst and kidney volume growth is directly correlated with a subsequent loss of GFR. However, the correlation was not perfect in these studies. This might be due to some measurement errors of GFR and kidney volume, as well as the difficulties adjusting for the heterogeneity of study subjects in terms of baseline age and normalizing kidney volume and GFR to body size. In addition, modifying factors might also affect GFR independent of their influence on cyst growth. Although kidney volume is not a perfect surrogate marker for studying early disease progression in ADPKD, at present it is certainly the best, in particular for proof-of-principle studies that need to rely on reasonable follow-up times.

Autosomal Dominant Polycystic Kidney

Disease

\section{Current Therapeutic Approaches for ADPKD}

The pathogenesis of cyst growth in ADPKD is complex and involves multiple signaling cascades [16-18]. Based on experimental research data, clinical trials have been initiated to examine the efficacy of various drugs which interfere with these signaling pathways in ADPKD, including the mammalian target of rapamycin (mTOR) inhibitors rapamycin (Rapamune ${ }^{\circledR}$ ) and everolimus (Certi$\left.\operatorname{can}^{\circledR}\right)$, the vasopressin V2 receptor antagonist OPC-41061 $\left(\right.$ Tolvaptan $\left.^{\circledR}\right)$, and the somatostatin analog octreotideLAR (Sandostatin $\operatorname{LAR}^{\circledR}$ ). Furthermore, a large study is testing the effect of inhibition of the renin-angiotensinaldosterone system (RAAS), using ACEI (angiotensinconverting enzyme inhibitor) and ARB (aldosterone receptor blocker) therapy. Table 2 summarizes the most important ongoing trials. Based on pathophysiological considerations and experimental animal models, some other drugs have been proposed, but these substances have not yet reached the stage of clinical trials and will not be discussed further.

\section{Use of mTOR Inhibitors to Treat ADPKD Disease Progression}

A hallmark of ADPKD is enhanced renal tubular epithelial cell proliferation. In various animal models of PKD and in human ADPKD the aberrant epithelial cell proliferation has clearly been linked to an activation of the mTOR pathway [19-22]. Furthermore, a direct physical interaction between the cytoplasmic tail of polycystin-1 (PC1) and tuberin (the product of the TSC2 gene that is known to regulate the kinase activity of mTOR) could be demonstrated [18]. Mutations in PC1 are thought to inappropriately promote the proliferation of cyst-lining epithelial cells in ADPKD via mTOR [23]. Hence, a therapy with mTOR inhibitors represents a promising strategy to inhibit the aberrant activation of the mTOR pathway in ADPKD. Both mTOR inhibitors rapamycin and everolimus have been shown to significantly retard the cyst growth and to preserve the renal function in several animal models of PKD [19-22].

Currently 4 prospective, randomized clinical trials with rapamycin and everolimus are in progress, and are summarized in table 2. Data on several additional case series have reported promising results at scientific meetings, some of which have been published in abstract form. Three of the 4 trials use kidney (cyst) volume change as the primary endpoint. These 4 trials are different in terms 
Table 2. Most important ongoing clinical trials testing drug efficacy on disease progression in ADPKD

\begin{tabular}{|c|c|c|c|c|c|c|}
\hline Study name & Study number & Study drug & Study design & Eligibility & $\begin{array}{l}\text { Patients } \\
\mathrm{n}\end{array}$ & $\begin{array}{l}\text { Treatment } \\
\text { duration, months }\end{array}$ \\
\hline $\begin{array}{l}\text { SUISSE } \\
\text { ADPKD }\end{array}$ & NCT00346918 & $\begin{array}{l}\text { Sirolimus } \\
2 \mathrm{mg} / \text { day }\end{array}$ & $\begin{array}{l}\text { Single center } \\
\text { Randomized } \\
\text { Open-label }\end{array}$ & $\begin{array}{l}18-40 \text { years old } \\
\mathrm{GFR}>70 \mathrm{ml} / \mathrm{min}\end{array}$ & 100 & 18 \\
\hline SIRENA & NCT00491517 & Sirolimus & $\begin{array}{l}\text { Single center } \\
\text { Randomized } \\
\text { Open-label } \\
\text { Crossover }\end{array}$ & $\begin{array}{l}18-80 \text { years old } \\
\text { GFR }>40 \mathrm{ml} / \mathrm{min}\end{array}$ & 16 & 6 \\
\hline $\begin{array}{l}\text { Sirolimus } \\
\text { in ADPKD }\end{array}$ & NCT00286156 & Sirolimus & $\begin{array}{l}\text { Single center } \\
\text { Randomized } \\
\text { Open-label } \\
\text { Dose comparison }\end{array}$ & $\begin{array}{l}18-75 \text { years old } \\
\text { I: GFR }>60 \mathrm{ml} / \mathrm{min} \\
\text { II: GFR } 25-59 \mathrm{ml} / \mathrm{min}\end{array}$ & 45 & 12 \\
\hline $\begin{array}{l}\text { Everolimus } \\
\text { in ADPKD }\end{array}$ & NCT00414440 & Everolimus & $\begin{array}{l}\text { Multicenter } \\
\text { Randomized } \\
\text { Placebo-controlled }\end{array}$ & $\begin{array}{l}18-65 \text { years old } \\
\text { GFR } 30-90 \mathrm{ml} / \mathrm{min}\end{array}$ & 400 & 24 \\
\hline $\begin{array}{l}\text { Tempo } 3 / 4 \\
\text { trial phase } 3\end{array}$ & NCT00428948 & Tolvaptan & $\begin{array}{l}\text { Multicenter } \\
\text { Randomized } \\
\text { Placebo-controlled }\end{array}$ & $\begin{array}{l}18-40 \text { years old } \\
\mathrm{GFR}>70 \mathrm{ml} / \mathrm{min}\end{array}$ & $1,200-1,500$ & 36 \\
\hline $\begin{array}{l}\text { ALADIN } \\
\text { trial }\end{array}$ & NCT00309283 & Somatostatin & $\begin{array}{l}\text { Single center } \\
\text { Randomized } \\
\text { Single blind }\end{array}$ & $\begin{array}{l}>18 \text { years old } \\
\text { GFR }>70 \mathrm{ml} / \mathrm{min}\end{array}$ & 66 & 36 \\
\hline $\begin{array}{l}\text { HALT-PKD } \\
\text { study A }\end{array}$ & NCT00283686 & $\begin{array}{l}\text { Lisinopril/Telmisartan vs. } \\
\text { Lisinopril/placebo and } \\
\text { low vs. standard BP }\end{array}$ & $\begin{array}{l}\text { Multicenter } \\
\text { Randomized } \\
\text { Placebo-controlled }\end{array}$ & $\begin{array}{l}15-49 \text { years old } \\
\mathrm{GFR}>60 \mathrm{ml} / \mathrm{min} \\
\mathrm{BP}>130 / 80 \mathrm{~mm} \mathrm{Hg}\end{array}$ & 548 & 48 \\
\hline $\begin{array}{l}\text { HALT-PKD } \\
\text { study B }\end{array}$ & NCT00283686 & $\begin{array}{l}\text { Lisinopril/Telmisartan vs. } \\
\text { Lisinopril/placebo }\end{array}$ & $\begin{array}{l}\text { Multicenter } \\
\text { Randomized } \\
\text { Placebo-controlled }\end{array}$ & $\begin{array}{l}18-64 \text { years old } \\
\text { GFR } 25-60 \mathrm{ml} / \mathrm{min}\end{array}$ & 472 & $\begin{array}{l}\text { Time to } \\
\text { endpoint }\end{array}$ \\
\hline
\end{tabular}

of patient number, patient characteristics and dose range used. The SUISSE ADPKD study (NCT00346918) enrolled 100 patients aged $18-40$ years with preserved renal function and uses sirolimus at $2 \mathrm{mg} /$ day for 18 months [24]. A German study (NCT00414440) enrolled 400 patients aged 18-65 years with CKD stage II/III and uses everolimus for 2 years at a higher dose. The Cleveland Clinic (NCT00286156) and the Bergamo (NCT00491517) studies involve a smaller patient population, using a dosefinding strategy. Definitive data from these 4 clinical trials will be available in 2010 .

\section{Use of Vasopressin V2 Receptor Antagonists to Treat ADPKD Disease Progression}

In addition to increased cell proliferation which may be targeted by mTOR inhibition, fluid secretion into cysts is thought to play a central role in the process of cyst enlargement. Fluid secretion and cell proliferation are driven in part by alterations in intracellular calcium homeostasis and cyclic adenosine monophosphate (cAMP) levels. These alterations can be explained by the fact that polycystin-1 and polycystin-2, the latter being a calcium-permeable cation channel, function together in specialized structures that sense the extracellular environment, such as primary cilia, focal adhesions and adherens complexes. Thus, hormone receptors such as the vasopressin V2 receptor which drive cAMP production in the kidney appear to be logical treatment targets. The V2 receptor antagonists (V2RA) OPC-31260 and tolvaptan inhibit cyst development in an animal model of PKD $\left(P k d^{-/ t m 1 S o m}\right.$ mouse, orthologous to human PKD2) [25]. Consistent with the lack of V2 receptor expression in liver tissue, V2RA had no effect on liver cysts.

The Tolvaptan Efficacy and Safety in Management of PKD and Outcomes (TEMPO) trial program consists of several studies. The results of the phase 2 studies sug- 
gested that tolvaptan is safe and well tolerated in ADPKD [26]. A large phase 3, placebo-controlled, double-blind study in 18- to 50-year-old patients with ADPKD and preserved renal function but relatively rapid progression, as indicated by a total kidney volume of $>750 \mathrm{ml}$, has been initiated and will determine whether tolvaptan is effective in slowing the progression of the disease (TEMPO 3/4 study; NCT00428948).

\section{Use of Somatostatin Analogs to Treat ADPKD Progression}

Somatostatin receptors are present in human kidneys [27] and influence chloride secretion via CFTR channels. Having observed stabilization of cyst volume in an ADPKD patient with pituitary adenoma who received somatostatin, Ruggenenti et al. [28] hypothesized that this agent might be beneficial in ADPKD. In a small crossover placebo-controlled pilot study, 12 patients were treated with somatostatin for 6 months and kidney volume growth was assessed by CT volumetry. During treatment with somatostatin, the percent increase in total kidney volume was significantly lower and cystic volume tended to increase less. A phase 3 , single center, randomized controlled study enrolling 66 patients $>18$ years with GFR $>40 \mathrm{ml} / \mathrm{min} / 1.73 \mathrm{~m}^{2}$ is now ongoing to validate these results using kidney volume change assessed by MRI as primary outcome (the ALADIN trial; NCT00309283). Furthermore, two trials have evaluated the effect of octreotide or another long-acting somatostatin analog, lanreotide, on polycystic liver volume (NCT00426153, which assesses kidney volume as a secondary endpoint, and NCT00565097, which has recently been completed and showed a small but significant effect on polycystic liver volume over 6 months [29]).

\section{Blood Pressure Control with ACEI and ARB to Treat ADPKD Progression}

Hypertension occurs early in patients with ADPKD and before the loss of renal function, and activation of the RAAS may play a role in the pathogenesis of hypertension as well as in the pathogenesis of cyst progression [30]. Thus, drugs that block the RAAS (renin inhibitors, ACEIs, ARBs, or aldosterone antagonists) could be renoprotective also in ADPKD. A few studies have previously tested the use of ACEIs in ADPKD. In a non-randomized study, hypertensive ADPKD patients treated with a diuretic had a faster GFR decline than those treated with ACEIs [31]. As compared with the calcium channel blocker amlodipine, enalapril significantly reduced proteinuria in hypertensive ADPKD patients in a randomized trial but had no effect on GFR decline [32]. The only placebo-controlled trial testing an ACEI in ADPKD showed no benefit [33]. However, these studies all included relatively old patients and used GFR as primary outcome. A recent study tested the use of ACEI in children with ADPKD and used kidney volume by ultrasonography as primary outcome. There was no significant treatment effect on renal growth in that study [34].

The HALT-PKD trial is an ongoing multicenter study designed to test whether blockade of RAAS and/or rigorous blood pressure control play a role in slowing renal progression during early and late phases in ADPKD (NCT00283686) [35]. In this prospective randomized controlled trial the independent effects of RAAS blockade using both ACEI and ARB as well as blood pressure lowering on renal disease progression in early (study A; $\mathrm{GFR},>60 \mathrm{ml} / \mathrm{min} ; \mathrm{n}=548$ ) and more advanced renal disease (study B; GFR, 25-60 ml/min; $\mathrm{n}=472$ ) are being tested. The ACEI lisinopril is prescribed for all patients in HALT (both studies A and B). Since it is not known whether the addition of an ARB, telmisartan, will provide renal or cardiovascular protection in ADPKD patients, patients in both studies A and B will be randomized to lisinopril plus placebo versus lisinopril plus telmisartan. In study $\mathrm{A}$, hypertensive and borderline hypertensive ( $>130 / 80 \mathrm{~mm} \mathrm{Hg}$ ) ADPKD subjects $15-50$ years of age are randomized in a $2 \times 2$ factorial design to lisinopril (ACEI) and placebo versus ACEI and telmisar$\tan (\mathrm{ARB})$ and two levels of blood pressure control: standard (120-130/70-80 mm Hg) versus rigorous goal (95$110 / 65-75 \mathrm{~mm} \mathrm{Hg}$ ). Study A uses a primary structural endpoint, change in total kidney volume over 4 years by MRI, as developed in CRISP. In study B, hypertensive and borderline hypertensive ADPKD subjects 18-65 years of age with GFR $25-60 \mathrm{ml} / \mathrm{min}$ are randomized to ACEI and placebo versus ACEI and ARB therapy with a single blood pressure goal of $110-130 / 80 \mathrm{~mm} \mathrm{Hg}$. The primary outcome is time to the composite endpoints of doubling of serum creatinine, ESRD, or death. Thus, in the HALT studies the relative benefits of blood pressure control and inhibition of the RAAS in both early and late stages of ADPKD will be established, which will guide clinicians regarding best practices for ADPKD patients. 


\section{Conclusions}

ADPKD progression can be reliably assessed by MR and CT imaging techniques and kidney volumetry. These procedures can be used to test the effect of new investigational drugs in early stages of the disease, when GFR is still preserved. In later stages of the disease, progression could be monitored by following the decline of GFR, but at that time therapeutic intervention might be too late to significantly affect outcome.

There is reasonable hope that disease progression in patients with ADPKD can be delayed with newer thera- peutic approaches which are currently being tested. At present, four treatment approaches which have been based on novel pathophysiological insights and animal data have been transferred to randomized clinical trials. Results from these ongoing studies will become available in 2010. Until then patients with ADPKD need to be advised to follow the current management recommendations, which at this time include optimal blood pressure control, sufficient fluid intake and avoidance of smoking and excessive caffeine intake.

\section{References}

1 Torres VE, Harris PC, Pirson Y: Autosomal dominant polycystic kidney disease. Lancet 2007;369:1287-1301.

2 Grantham JJ: Clinical practice: autosomal dominant polycystic kidney disease. N Engl J Med. 2008;359:1477-1485.

3 Cheong B, Muthupillai R, Rubin MF, Flamm $\mathrm{SD}$ : Normal values for renal length and volume as measured by magnetic resonance imaging. Clin J Am Soc Nephrol 2007;2:3845.

4 Churchill DN, Bear JC, Morgan J, Payne RH, McManamon PJ, Gault MH: Prognosis of adult onset polycystic kidney disease reevaluated. Kidney Int 1984;26:190-193.

$\checkmark 5$ Hateboer N, v Dijk MA, Bogdanova N, Coto E, Saggar-Malik AK, San Millan JL, Torra R, Breuning M, Ravine D: Comparison of phenotypes of polycystic kidney disease types 1 and 2. European PKD1-PKD2 Study Group. Lancet 1999;353:103-107.

6 Dalgaard OZ: Bilateral polycystic disease of the kidneys; a follow-up of two hundred and eighty-four patients and their families. Acta Med Scand Suppl 1957;328:1-255.

7 Fick-Brosnahan GM, Belz MM, McFann KK, Johnson AM, Schrier RW: Relationship between renal volume growth and renal function in autosomal dominant polycystic kidney disease: a longitudinal study. Am Kidney Dis 2002;39:1127-1134.

$\checkmark 8$ Fick-Brosnahan GM, Tran ZV, Johnson AM, Strain JD, Gabow PA: Progression of autosomal-dominant polycystic kidney disease in children. Kidney Int 2001;59:1654-1662.

9 Grantham JJ, Torres VE, Chapman AB, Guay-Woodford LM, Bae KT, King BF Jr, Wetzel LH, Baumgarten DA, Kenney PJ, Harris PC, Klahr S, Bennett WM, Hirschman GN, Meyers CM, Zhang X, Zhu F, Miller JP; CRISP Investigators: Volume progression in polycystic kidney disease. N Engl J Med 2006;354:2122-2130.
10 Kistler AD, Poster D, Krauer F, Weishaupt D, Raina S, Senn O, Binet I, Spanaus K, Wüthrich RP, Serra AL: Increases in kidney volume in autosomal dominant polycystic kidney disease can be detected within 6 months. Kidney Int 2009;75:235-241.

11 Grantham JJ, Chapman AB, Torres VE: Volume progression in autosomal dominant polycystic kidney disease: the major factor determining clinical outcomes. Clin J Am Soc Nephrol 2006;1:148-157.

12 King BF, Reed JE, Bergstralh EJ, Sheedy PF 2nd, Torres VE: Quantification and longitudinal trends of kidney, renal cyst, and renal parenchyma volumes in autosomal dominant polycystic kidney disease. J Am Soc Nephrol 2000;11:1505-1511.

13 Sise C, Kusaka M, Wetzel LH, Winklhofer F, Cowley BD, Cook LT, Gordon M, Grantham JJ: Volumetric determination of progression in autosomal dominant polycystic kidney disease by computed tomography. Kidney Int 2000;58:2492-2501.

14 Antiga L, Piccinelli M, Fasolini G, Ene-Iordache B, Ondei P, Bruno S, Remuzzi G, Remuzzi A: Computed tomography evaluation of autosomal dominant polycystic kidney disease progression: a progress report. Clin J Am Soc Nephrol 2006;1:754-760.

15 Bae KT, Tao C, Zhu F, Bost JE, Chapman AB, Grantham JJ, Torres VE, Guay-Woodford LM, Meyers CM, Bennett WM; Consortium for Radiologic Imaging Studies Polycystic Kidney Disease: MRI-based kidney volume measurements in ADPKD: reliability and effect of gadolinium enhancement. Clin J Am Soc Nephrol 2009;4:719-725.

16 Torres VE, Harris PC: Mechanisms of disease: autosomal dominant and recessive polycystic kidney diseases. Nat Clin Pract Nephrol 2006;2:40-55.

17 Torres VE, Harris PC: Polycystic kidney disease: genes, proteins, animal models, disease mechanisms and therapeutic opportunities. J Intern Med 2007;261:17-31.
18 Torres VE, Harris PC: Autosomal dominant polycystic kidney disease: the last 3 years. Kidney Int 2009;76:149-168.

19 Tao Y, Kim J, Schrier RW, Edelstein CL: Rapamycin markedly slows disease progression in a rat model of polycystic kidney disease. J Am Soc Nephrol 2005; 16:46-51.

20 Wahl PR, Serra AL, Le Hir M, Molle KD, Hall MN, Wüthrich RP: Inhibition of mTOR with sirolimus slows disease progression in Han:SPRD rats with autosomal dominant polycystickidney disease (ADPKD). Nephrol Dial Transplant 2006;21:598-604.

21 Shillingford JM, Murcia NS, Larson CH, Low SH, Hedgepeth R, Brown N, Flask CA, Novick AC, Goldfarb DA, Kramer-Zucker A, Walz G, Piontek KB, Germino GG, Weimbs $\mathrm{T}$ : The mTOR pathway is regulated by polycystin-1, and its inhibition reverses renal cystogenesis in polycystic kidney disease. Proc Natl Acad Sci USA 2006;103:54665471.

22 Wu M, Wahl PR, Le Hir M, Wackerle-Men Y, Wüthrich RP, Serra AL: Everolimus retards cyst growth and preserves kidney function in a rodent model for polycystic kidney disease. Kidney Blood Press Res 2007;30:253-259.

23 Mostov KE: mTOR is out of control in polycystic kidney disease. Proc Natl Acad Sci USA 2006;103:5247-5248.

24 Serra AL, Kistler AD, Poster D, Struker M, Wüthrich RP, Weishaupt D, Tschirch F: Clinical proof-of-concept trial to assess the therapeutic effect of sirolimus in patients with autosomal dominant polycystic kidney disease: SUISSE ADPKD study. BMC Nephrol 2007;8:13.

25 Torres VE, Wang X, Qian Q, Somlo S, Harris PC, Gattone VH 2nd: Effective treatment of an orthologous model of autosomal dominant polycystic kidney disease. Nat Med 2004;10:363-364.

26 Torres VE: Vasopressin antagonists in polycystic kidney disease. Semin Nephrol 2008; 28:306-317. 
-27 Reubi JC, Horisberger U, Studer UE, Waser B, Laissue JA: Human kidney as target for somatostatin: high affinity receptors in tubules and vasa recta. J Clin Endocrinol Metab 1993;77:1323-1328.

-28 Ruggenenti P, Remuzzi A, Ondei P, Fasolini G, Antiga L, Ene-Iordache B, Remuzzi G, Epstein FH: Safety and efficacy of long-acting somatostatin treatment in autosomal-dominant polycystic kidney disease. Kidney Int 2005;68:206-216.

29 van Keimpema L, Nevens F, Vanslembrouck $\mathrm{R}$, van Oijen MG, Hoffmann AL, Dekker HM, de Man RA, Drenth JP: Lanreotide reduces the volume of polycystic liver: a randomized, double-blind, placebo-controlled trial. Gastroenterology 2009 [Epub ahead of print].
30 Schrier RW: Optimal care of autosomal dominant polycystic kidney disease patients. Nephrology (Carlton) 2006;11:124-130.

-31 Ecder T, Edelstein CL, Fick-Brosnahan GM, Johnson AM, Chapman AB, Gabow PA, Schrier RW: Diuretics versus angiotensinconverting enzyme inhibitors in autosomal dominant polycystic kidney disease. Am J Nephrol 2001;21:98-103.

32 Ecder T, Chapman AB, Brosnahan GM, Edelstein CL, Johnson AM, Schrier RW: Effect of antihypertensive therapy on renal function and urinary albumin excretion in hypertensive patients with autosomal dominant polycystic kidney disease. Am J Kidney Dis 2000;35:427-432.
33 van Dijk MA, Breuning $\mathrm{MH}$, Duiser R, van Es LA, Westendorp RG: No effect of enalapril on progression in autosomal dominant polycystic kidney disease. Nephrol Dial Transplant 2003;18:2314-2320.

34 Cadnapaphornchai MA, McFann K, Strain JD, Masoumi A, Schrier RW: Prospective change in renal volume and function in children with ADPKD. Clin J Am Soc Nephrol 2009;4:820-829.

35 Chapman AB: Approaches to testing new treatments in autosomal dominant polycystic kidney disease: insights from the CRISP and HALT-PKD studies. Clin J Am Soc Nephrol 2008;3:1197-1204. 